\title{
TRANSFORMACIONES AGRARIAS RECIENTES EN LA LAGUNA DE SAN BENITO. LA ÚLTIMA FASE DE LA OCUPACIÓN DE UN ESPACIO NATURAL
}

\author{
Gabino Ponce Herrero
}

\section{Situación y configuración de la laguna.}

La laguna de San Benito se encuentra ubicada entre los términos municipales de Ayora (Valencia) y Almansa (Albacete), ocupando el fondo del gran valle corredor que, con dirección meridiana, pone en contacto ambas poblaciones. La cuenca endorreica, con una superficie vertiente de unos $90 \mathrm{~km}^{2}$ y una cubeta de inundación de aproximadamente $4,5 \mathrm{~km}^{2}$, cerrada por la isohipsa de $680 \mathrm{~m}$, se halla enmarcada por los relieves del Mugrón al Oeste y las estribaciones suroccidentales del macizo del Caroig y los pliegues de la Sierra de Almansa por el Este ${ }^{1}$. Hacia el Norte la cuenca queda separada de la Rambla de La Peña, que vierte aguas al Júcar, por los depósitos cuaternarios en forma de glacis-cono que descienden de las estructuras cretácicas del Caroig. Por el Sur queda individualizada por la convergencia del glacis de la Sierra de Almansa y el gran cono de deyección de la Rambla del Pantano, que marcan un umbral a $685 \mathrm{~m}$ de altitud, entre Casa Mancorra y Casa La Estacada, en una línea Oeste-Este que señalaría aproximadamente la divisoria de aguas entre la cubeta de San Benito y el área endorreica de la huerta Norte de Almansa.

El afloramiento triásico de carácter diapírico ha sido el causante de la apertura del gran valle estructural Ayora-Almansa, sobre el que los procesos de erosión y acumulación posteriores han compartimentado, con sus depósitos, una serie de cubetas endorreicas alineadas de Norte a Sur según el rumbo del Trías.

1 FELIUCASTELLA, A., 1972 «La Laguna de San Benito (Valencia-Albacete», Cuadernos de Geografía, n. ${ }^{\circ} 11$, Valencia, pp. $79-89$. 
La carencia de avenamiento exorreico queda explicada también por las acusadas condiciones de aridez. Las escasas precipitaciones y su marcada concentración en el tiempo determinan la ausencia de cursos de agua permanentes, que pudieran haber desbordado y encajado los umbrales endorreicos. La

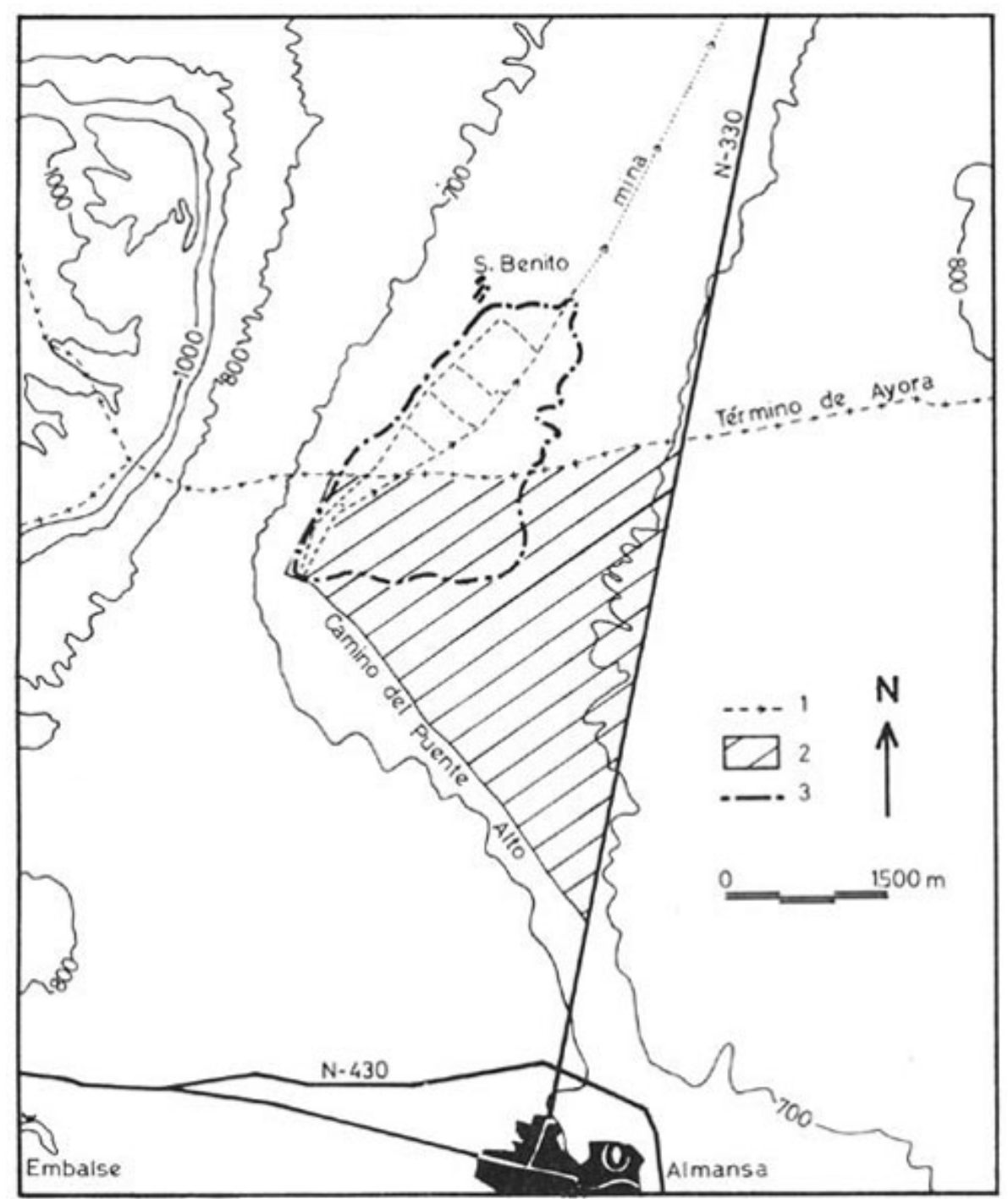

FIGURA 1. Localización de la laguna y del área transformada. En la leyenda: 1, red de azarbes; 2, superficie transformada; 3, perímetro que alcanzó la laguna con las inundaciones de 1984 (coincide con la cota de 670m). 
aridez de las tierras provoca la rápida infiltración de las aguas que discurren sobre los materiales detríticos cuaternarios, de ahí que la mayor parte de los cursos sean influentes, es decir, experimentan una pérdida constante de caudales por infiltración en sus cauces. Así, tanto en superficie, en forma de manto de agua, o de manera hipogea todas las aguas confluyen en el fondo de la depresión, formando una cuenca hipogea con un elevado nivel freático mantenido por un substrato impermeable formado por las arcillas del Keuper. Es en los momentos equinocciales cuando, con frecuencia, las precipitaciones rebasan el umbral de saturación y se acumulan en superficie formando la laguna.

El substrato impermeable y la periódica alimentación han determinado la presencia de una masa de agua casi perenne en el fondo de la cubeta hasta principios del siglo XIX, momento en que se acometen las obras para su desecación. Con posterioridad a éstas ha vuelto a enlagunarse al menos en cuatro ocasiones, la última como consecuencia de las lluvias de noviembre de 1984.

\section{La laguna como espacio natural.}

Las noticias que hacen referencia a la riqueza faunística de estas tierras enlagunadas se remontan al siglo XIV y aparecen en el Libro de la Caza de don Juan Manuel, en el que señala la riqueza cinegética de los almarjales de la comarca ${ }^{2}$. En el siglo XVIII, las respuestas al interrogatorio del Diccionario de Tomás López manifiestan también la presencia de varias especies de aves acuáticas:

«... abriendo madre que guía las aguas a una laguna que llaman de San Benito, y ocupa parte de este término y del de Ayora, de un cuarto de legua de circunferencia, donde causa daño en los bancales que ocupa, y aquellas inmediaciones algunas terzianas por la corrupción del Ayre y acuden Aves de Agua como patos, gansos, Anades colliverdes y otras que suelen cazarse desde Barcas» ${ }^{3}$.

En la actualidad, después de las inundaciones de 1982 y las de 1984, continuadas durante 1985, la laguna ha recobrado su misión de lugar de reposo de las aves migradoras y son varias las especies de esta índole que pueden observarse en sus aguas.

\section{La colonización de la laguna.}

La fertilidad de las tierras de las márgenes y el fondo de la cubeta endorreica en relación con el secano colindante es un hecho conocido, al menos,

2 MANUEL, DON JUAN, 1982, Libro de la caza, Ed. Blecua. Gredos, Madrid, pp. 578-579.

3 LÓPEZ, T., 1786, Diccionario Geográfico, Biblioteca Nacional, ms. 7.293, respuesta n. ${ }^{\text {o }}$ 4, fol. 75. 
desde la ocupación árabe. Así, este paraje, tras la conquista cristiana quedó reservado, como uno de los más fértiles, para el propio monarca Alfonso X quién en 1264 lo cedió a los colonos que fuesen a repoblar Almansa:

«Otrossi por fazer merçed damos les el heredamiento que dizen el Hondón del Almugrón assí commo va del algibe que está en la carrera de Ayora contra Almansa» ${ }^{4}$.

La nota citada del Diccionario de Tomás López expresa de forma manifiesta la presencia de campos de cultivos dañados por las aguas. Unos años más tarde es Cavanilles quién se ocupa de la laguna:

«Son raros los años en que llega a secarse enteramente, como la vi en 1792, y aun entonces queda inútil aquel suelo fértil, porque ni los operarios se atreven a tragar el veneno que la tierra despide al darle vueltas, ni los propietarios quieren aventurar gastos y semillas, estando ciertos de perderlo todo en la primera tempestad o aguacero... Para cortar la raíz del mal y reducir a cultivo el precioso fondo de la laguna convendría dar curso libre a sus aguas... $\rangle^{5}$.

A principios del siglo XIX, Chaix al referirse a la laguna de San Benito señala:

«Son tan raros los años que llega a secarse enteramente, que en el siglo pasado sólo tres veces se logró pisar el suelo; en este caso es tan feraz que produce un cahíz de trigo por cada hanegada» ${ }^{6}$.

Así, por razones económicas y de salubridad se iniciaron en 1804 las obras de desecación, concluidas en 1815 tras el paréntesis de la Guerra de la Independencia. En esencia, los trabajos constan de dos grandes azarbes que se abren desde la casa de El Blanco de Arriba hacia el Norte: uno bordea la orilla occidental hasta el caserío de San Benito para recoger las aguas de la vertiente del Mugrón y otro, el principal, atraviesa la laguna por su centro. Ambos se encuentran comunicados por seis zanjas menores que cruzan transversalmente la laguna y encauzan las aguas en el azarbe principal, conectado con una mina de $7 \mathrm{~km}$ que, por debajo del glacis-cono del Caroig, desagua en la Rambla de La Peña, tributaria del Júcar. Con todo, la obstrucción por entarquinamiento

4 ARCHIVO HISTÓRICO PROVINCIAL DE ALBACETE, Sec. Municipios, carp. 4, doc. 7: 1264, octubre, 9, SEVILLA. Concesión del Fuero de Cuenca y algunas heredades a los pobladores de Almansa, en PRETEL MARÍN, A., 1981, Almansa Medieval. Una villa del señorío de Villena en los s. XIII, XIV, y XV, Ayunt. Almansa, ap. doc., doc. II, p. 181.

5 CAVANILLES, A. J., 1795-1797, Observaciones sobre la Historia Natural, Geografía, Agricultura, Población y frutos del Reyno de Valencia, Madrid, t. II, 338 pp., pp. 3-4.

6 CHAIX, E., 1802, Una noticia de las lagunas y terrenos pantanosos de este Reino. Memoria premiada por la Real Sociedad Económica de Valencia, Imp. Benito Monfort, pp. 13-28. 
de la galería ha sido la causa de la reaparición de la laguna en varias ocasiones con posterioridad a su saneamiento.

\section{La ocupación agraria.}

En un informe realizado en 1959 para la Vicesecretaría Provincial de Ordenación Económica de Albacete se recoge cómo el área desecada de la laguna continuaba siendo ocupada por cereales, al tiempo que se señala la necesidad de implantar otros cultivos más rentables que aprovechen mejor la riqueza potencial de la zona ${ }^{7}$. En efecto, la mina de desagüe cuenta con una compuerta que permite regular el grado de humedad de las tierras, de manera que ésta sólo se abre cuando el empapado del suelo es suficiente y permite preveer rendimientos óptimos en la cosecha. El sistema potencia la dedicación cerealista del área por la inercia del campesino, que año tras año obtiene buenas cosechas, así como por su previsión, ya que el rigor climático hace grande el riesgo de heladas tardías en cultivos hortofrutícolas y las esporádicas inundaciones aconsejan no invertir demasiado capital y esfuerzo.

La feracidad de estas tierras ha fomentado desde antiguo el interés de los agricultores y de los inversores rentistas, de forma que el terrazgo se ha ido dividiendo por continuas adquisiciones y transmisiones hereditarias. Una somera distribución de la propiedad puede establecerse de la declaración de propiedades de los interesados en la desecación de la laguna en $1803^{8}$ :

\section{CUADRO I}

Distribución de la propiedad de la tierra en la laguna de San Benito en 1803

\section{Propietarios}

Vecinos de Almansa con explotaciones en término de Almansa.

Vecinos de Almansa con explotaciones en término de Ayora....

Vecinos de Ayora con explotaciones en término Ayora.

Totales

\begin{tabular}{|c|c|c|}
\hline$N .^{o}$ & Supf. Ha. & $\begin{array}{l}\text { Supf. media } \\
\text { Explot. Ha. }\end{array}$ \\
\hline 31 & 227,6 & 7,3 \\
\hline 10 & 121,0 & 12,1 \\
\hline 18 & 124,3 & 12,4 \\
\hline 59 & 472,9 & 8,0 \\
\hline
\end{tabular}

Fuente: Arch. Juan Arocas, Almansa, elaboración propias.

7 DELEGACIÓN PROVINCIAL DE SINDICATOS, 1959, Informe, 6 fols. mecanogr., Albacete.

8 ARCHIVO JUAN AROCAS, Almansa, en FELIU CASTELLA, A, 1972, ob. cit., p. 88. 
La falta de datos impide conocer con más detalle la estructura de la propiedad, con todo, la superficie media por explotación, $8 \mathrm{Ha}$, pone de manifiesto el grado de minifundismo si se tiene presente la orientación cerealista de las tierras en la laguna.

En 1966 la distribución de la propiedad y la estructura parcelaria del sector almanseño de la laguna y sus márgenes, es decir, la laguna en sentido estricto más el Hondo de Almansa, era la que expresa el cuadro II $^{9}$. En el análisis de cada uno de los intervalos más significativos se observa un elevado porcentaje de pequeñas unidades de producción que supone una grave acumulación de las explotaciones en los primeros grupos, de forma que la mitad de los propietarios cuentan con predios inferiores a las $2 \mathrm{Ha}$. Un total de 58 agricultores se reparten sólo 54 Ha de terreno, esto es, tan sólo el 6,6\% de la superficie analizada. El minifundismo queda patente si se tiene en cuenta que el $85,9 \%$ de los propietarios lo son de explotaciones menores de $10 \mathrm{Ha}$ y sólo se reparten el 28,5\% de las tierras. La propiedad media, entendida como la comprendida entre las $10 \mathrm{Ha}$ y las $100 \mathrm{Ha}$, integra a 15 agricultores, esto es, el 13,2\% del total, -que se reparten el 46,6\% de las tierras, lo que supone una proporción aceptable. La gran propiedad, con más de $100 \mathrm{Ha}$, sólo cuenta con una representación: la finca que con $204 \mathrm{Ha}$ ocupa la cuarta parte de la superficie total en estudio.

Sobre el mapa catastral se comprueba la distribución homogénea de las parcelas, de forma que las más pequeñas se ubican indefectiblemente en la zona más húmeda y con mayores rendimientos, es decir, en el lecho de la laguna, donde el aporte hídrico está asegurado y, además, de forma regulada. Los predios ganan magnitud conforme se alejan de sus márgenes y ascien-

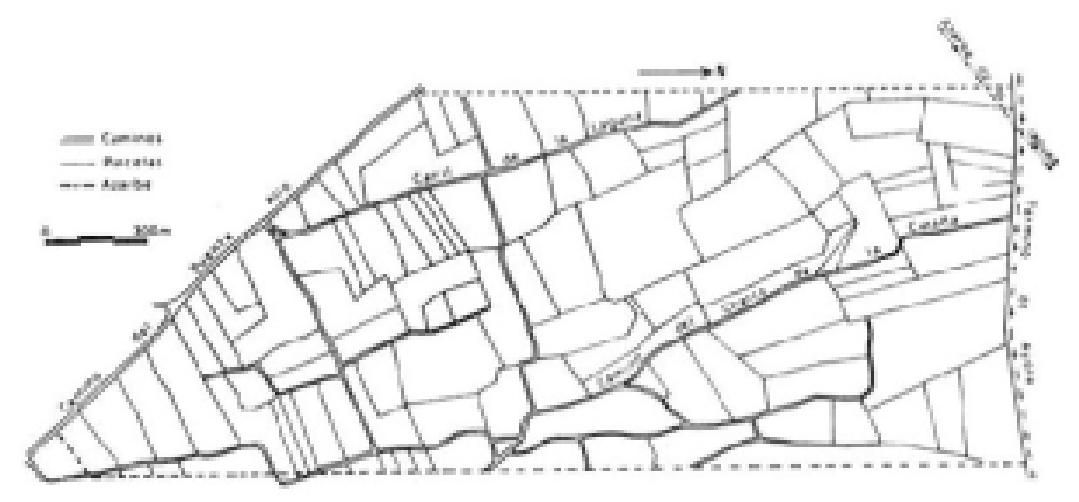

FIGURA 2. Detalle del parcelario de un sector del área transformada antes de iniciarse los trabajos.

9 Mins. Agri., INC., 1967, «Memoria», Proyecto de Plan general de colonización de la zona regable con aguas subterráneas de Almansa (Albacete), 2. ${ }^{\text {a }}$ parte, Valencia, p. 10. 
den por la suave topografía del glacis-cono de la Atalaya (Sierra de Almansa), de manera que en las cotas más elevadas, y con una disposición que sigue a grandes rasgos las curvas de nivel, se extienden las medianas y grandes unidades de producción.

\section{CUADRO II}

Distribución de la propiedad y estructura parcelaria en el Hondo de Almansa (incluye la porción almanseña de la Laguna de San Benito)

\begin{tabular}{|c|c|c|c|c|c|c|c|c|}
\hline \multirow[b]{2}{*}{ Intervalo } & \multirow[b]{2}{*}{ N. ${ }^{o}$ prop } & \multirow[b]{2}{*}{$\%$} & \multirow[b]{2}{*}{$\%$ acum } & \multicolumn{2}{|c|}{$N .^{o}$ de parcelas } & \multicolumn{3}{|c|}{ Superficie } \\
\hline & & & & Total & Prop media & & Ia & $\%$ \\
\hline$<1 \mathrm{Ha}$. & $\frac{\text { acum. }}{34}$ & 29,8 & 29,8 & 39 & 1,1 & 19 & 2,3 & 2,3 \\
\hline $1-2$ & 24 & 21,1 & 50,9 & 29 & 1,2 & 35 & 4,3 & 6,6 \\
\hline $2-3$ & 15 & 13,2 & 64,1 & 20 & 1,3 & 38 & 4,7 & 11,3 \\
\hline $3-5$ & 11 & 9,6 & 73,7 & 24 & 2,2 & 42 & 5,1 & 16,4 \\
\hline $5-10$ & 14 & 12,2 & 85,9 & 33 & 2,4 & 99 & 12,1 & 28,5 \\
\hline $10-15$ & 7 & 6,1 & 92,0 & 40 & 5,7 & 92 & 11,3 & 39,8 \\
\hline $15-30$ & 4 & 3,5 & 95,5 & 24 & 6,0 & 79 & 9,7 & 49,5 \\
\hline $30-50$ & 2 & 1,8 & 97,3 & 37 & 18,5 & 66 & 8,1 & 57,6 \\
\hline $50-100$ & 2 & 1,8 & 99,1 & 28 & 14,0 & 143 & 17,5 & 75,1 \\
\hline \multirow[t]{2}{*}{$>100$} & 1 & 0,9 & 100 & 10 & 10,0 & 204 & 24,9 & 100 \\
\hline & 114 & 100 & & 284 & 2,5 & 817 & 100 & \\
\hline
\end{tabular}

Fuente: INC, 1967, ob. cit., p. 10, elaboración propia.

El régimen de tenencia dominante es el directo y el sistema de cultivo empleado el de cereal de año y vez, con un reparto proporcional en las fincas medianas y grandes del suelo entre trigo, el $25 \%$ de la explotación, cebada, otro 25\%, y el resto de barbecho. Muchos de estos predios son parcelas disociadas de explotaciones mayores extendidas por el secano.

\section{Los proyectos de transformación en regadío.}

Las primeras tentativas de transformar el paraje del Hondo y la porción almanseña de la laguna surgen en Almansa a tenor de la creación en 1952 del Servicio Nacional de Concentración Parcelaria y de la puesta en funcionamiento del Plan Nacional de Actuación Regional, cuya primera muestra fue el Plan Badajoz iniciado en ese mismo año.

En 1954 se produce la solicitud de inclusión del término de Almansa en el Plan de Actuación del Instituto Nacional de Colonización, año en el que comienzan los estudios para conocer la viabilidad de su inclusión. En 1957 se realizan cinco sondeos con un aforo total de $216 \mathrm{l} / \mathrm{sg}$, pero los trabajos se interrumpen hasta 1964, año en el que, al reanudarlos, se comprueba la merma 
del aforo hasta un total de 173,2 1/sg. En 1964 y 1966 la Hermandad Sindical de Labradores de Almansa solicita la actuación del INC en el paraje del Hondo, petición acompañada por la propuesta de declaración de interés nacional de los regadíos, solicitudes aprobadas por el Consejo de Ministros en diciembre de 1966, iniciándose los trabajos previos al año siguiente. En 1972 se procede a la parcelación de la zona, en 1974 a la construcción de viales, en 1977 se finalizan las canalizaciones y por fin en 1983 se dan por concluidos los trabajos, que consisten en: el alumbramiento de caudales subterráneos para el riego, la dotación de líneas de alta tensión y de una estación transformadora para elevar el agua e impulsarla por la red de acequias que también fue preciso construir, así como algunos desagües que comunican con los azarbes de la laguna. La remodelación parcelaria exigió una nueva trama de caminos, construidos de tierra compactada formando talud, al tiempo fue precisa la nivelación y el abancalamiento de las parcelas para salvar el ligero desnivel y mejor aprovechamiento del riego.

Los análisis previos de suelos pusieron de manifiesto la pobreza en materia orgánica y la necesidad de grandes aportaciones de estiércol en los primeros años de cultivo en regadío ${ }^{10}$. Los suelos fueron clasificados en cuatro categorías según la textura, el contenido en materia orgánica y sales, la retención de agua, aireación y permeabilidad, como expresa el cuadro III.

\section{CUADRO III}

Aptitud agraria de los suelos del Hondo y la Laguna de San Benito

\begin{tabular}{lccc}
\multicolumn{1}{c}{ Clase } & Supf. Ha. & $\%$ \\
Primera & & 331 & 40,1 \\
Segunda & 247 & 29,9 \\
Tercera & 194 & 23,5 \\
Regable con limitaciones & & 53 & 6,5 \\
\multicolumn{1}{r}{ Totales.................. } & 825 & 100
\end{tabular}

Fuente: INC, 1967, ob. cit., p. 16

Los cálculos para la dotación de agua previeron unas necesidades de 0,56 1/sg y Ha en los meses de mayor exigencia, con una eficacia del sistema de riego del $80 \%$. Con el aforo existente en el momento, 216 1/sg después de la recuperación de algunos pozos, y partiendo de un funcionamiento intensivo durante 22 horas al día de la estación elevadora, la superficie susceptible de riego era sólo de $353 \mathrm{Ha}$, es decir, el 42,8\% de las tierras colonizadas, imponiéndose la búsqueda de nuevos caudales para regar las 472 Ha restantes.

10 Mins. Agri., INC., 1977, ob. cit., p. 16. 
Con todo, las previsiones no se cumplieron y en 1977 el aforo de los cinco pozos era sólo de 180 1/sg y la superficie regada nada más que $194 \mathrm{Ha}$, esto es, el 23,5\% de la prevista inicialmente. La perforación de dos nuevos pozos en Venta Galopa (junto a la presa del embalse de Almansa), con un aforo conjunto teórico de 300 1/sg, ha posibilitado la ampliación de la superficie regada total a $325 \mathrm{Ha}$, de forma que en la actualidad sólo el 39,4\% de la tierra susceptible de regadío en los planes iniciales ha sido transformada.

Los cinco primeros pozos se encuentran en la parte más baja del área regable y el agua tiene que ser bombeada desde la balsa donde se recoge de su extracción hasta el punto más alto del terreno transformado, desde donde la red de acequias la distribuye por gravedad, recogiéndose los sobrantes en desagües y azarbes que la conducen al azarbe principal de la laguna. El agua de Venta Galopa es conducida al área regada por el canal de riegos del embalse de Almansa y una prolongación hasta el Hondo, donde conecta con la red de acequias en su parte más elevada.

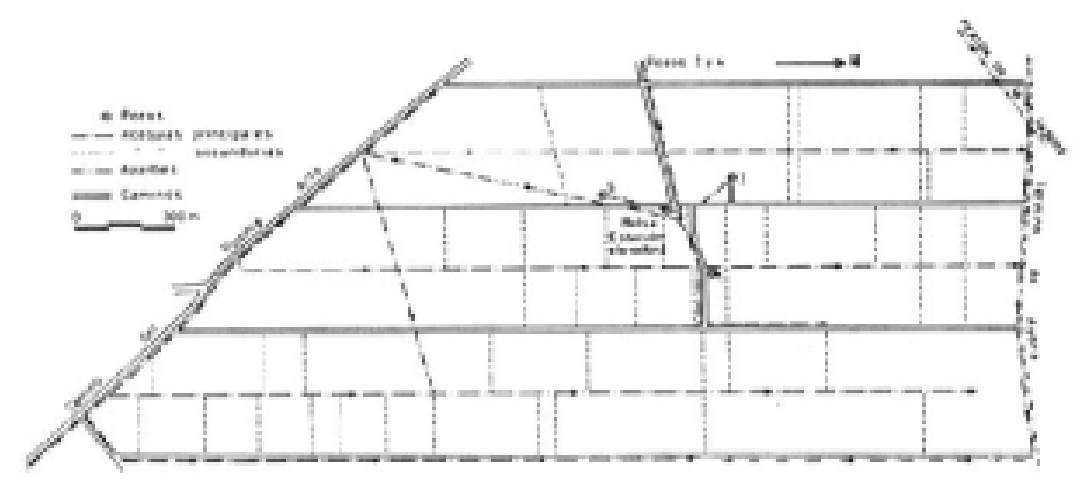

\section{La ocupación agraria reciente.}

Una vez concentradas las parcelas y dotadas de agua, la tierra fue dividida en tres partes para su reparto:

1. Una parte fue reservada a los antiguos propietarios que llevaban la explotación de forma directa: si su predio era inferior a las $60 \mathrm{Ha}$ la reserva cubría la totalidad de la finca; si era superior, la reserva afectaba a 60 Ha más la cuarta parte del resto de la superficie en propiedad. Además existía la opción de renunciar a la reserva correspondiente a cambio de lotes de $15 \mathrm{Ha}$ da hijo del antiguo propietario, sin que el monto total sobrepasara $120 \mathrm{Ha}$. La tierra reservada ascendió a 687,9 Ha. 
2. Las tierras no susceptibles de transformación o ya transformadas por iniciativa particular en el momento de la realización de las obras formaron otro grupo al margen del reparto.

3. Las restantes tierras, más las que no estuviesen cultivadas directamente por sus propietarios, así como las no reclamadas por reserva y las vendidas o permutadas durante los trabajos de reforma sin la autorización del INC, fueron empleadas en las instalaciones necesarias y repartidas las sobrantes en lotes de $15 \mathrm{Ha}$ entre nuevos colonos. En total sumaron 144,6 Ha que, junto a la superficie reservada, elevaban el área colonizada a 832,5 Ha.

Era intención del INC ofrecer lotes de tierra que permitiesen un nivel de vida aceptable para la familia campesina, por ello, dados los fuertes costes de la elevación y propulsión del agua, se imponía que los cultivos tuviesen la menor demanda posible de agua y, a la vez, fuesen de notable interés económico. En los lotes de $15 \mathrm{Ha}$ la superficie útil para cultivo, descontada la correspondiente a caminos dentro de la unidad, acequias y desagües, es de 14,25 $\mathrm{Ha}$, de las cuales $5,25 \mathrm{Ha}$ debían dedicarse a manzanos, 4,5 Ha a perales y el resto, 4,5 $\mathrm{Ha}$, a cultivos herbáceos en tres hojas, en dos de las cuales se repite el cultivo y en la tercera se siembra alfalfa, que debe permanecer cuatro años en el terreno ${ }^{11}$. Esta distribución de los nuevos predios debía ser la norma en las demás explotaciones.

Los nuevos colonos fueron seleccionados a partir del criterio básico de no poseer más tierras o tener en cantidad insuficiente para el mantenimiento de la familia. Así, en primer lugar fueron aceptados arrendatarios o aparceros de las tierras afectadas por la transformación y pequeños propietarios con explotaciones inviables, quedando después el cupo abierto a otros colonos.

Las directrices marcadas por el Ministerio de Agricultura, tanto para las actuaciones oficiales como para las particulares, señalaban la necesidad de que los nuevos regadíos pudiesen ser fácilmente mecanizables, dada la escasez de mano de obra y su elevado coste; que los productos herbáceos pudiesen ser transformados inmediatamente en carne y leche y que se dispusiesen unas estructuras comerciales ágiles, capaces de asegurar la venta desde los primeros momentos de la transformación, orientando la producción hacia la demanda ${ }^{12}$.

El proyecto chocó de inmediato con la falta de conocimientos de las técnicas del regadío de los agricultores almanseños -en las disposiciones para la selección de colonos se hace hincapié en la preferencia que tendrán los agricultores «con probados conocimientos en la práctica del regadío ${ }^{13}$-; con el trasvase continuo de mano de obra agraria a la industria y con la fiebre desatada a finales de los años sesenta y primera mitad de los setenta respecto al

11 Mins. Agri., INC., 1967, ob. cit., p. 19.

12 Mins. Agri., Deleg. Prov. Albacete, 1974, Ordenación de las producciones agrarias para el aprovechamiento de aguas subterráneas, Albacete, 71 pp. y mapa, p. 7.

13 Mins. Agri., INC., 1967, ob. cit., p. 23. 
cultivo del manzano, que pasó en Almansa de ocupar una superficie de 520 Ha en 1960 a 2.200 Ha en 1975, superficie que supone en este año el 57,7\% del total regado, restándole extensión a los cultivos forrajeros y atención al desarrollo ganadero ${ }^{14}$.

La saturación del mercado interior a partir de 1975 y la pésima comercialización, siempre a merced de intermediarios, fueron determinantes y en la segunda mitad del decenio se procedió a levantar los frutales, siendo sustituidos por cultivos cuya selección ha quedado sujeta al libre albedrío de los agricultores, a su preparación técnica, a su interés o desencanto y a su capacidad financiera. Los cultivos herbáceos han vuelto a ocupar la mayor parte de las explotaciones: cereales de invierno y maíz en verano, con costes mínimos de producción y de mano de obra, con la venta asegurada por el SENPA y hoy por una buena demanda.

\section{7. las mutaciones en el paisaje.}

Hasta que se realizaron las obras para el avenamiento de la laguna a principios del siglo pasado la antropización del paisaje era mínima. La laguna, con sus intermitencias, constituía el elemento fundamental del paisaje, con sus márgenes cubiertas de carrizales refugio y descanso de aves migradoras. En los alrededores se extendían los cereales de año y vez formando un paisaje sin solución de continuidad por todo el paraje del Hondo. Las parcelas, de tamaño y formas irregulares se sucedían unas a otras sin muretes ni obstáculos en sus límites, levemente inclinadas en el sentido de la pendiente.

Un paisaje similar podía observarse antes de las transformaciones del INC-IRYDA. Ahora, los campos han sido nivelados, separados por muretes, alambradas, acequias y desaguies; las parcelas adoptan formas geométricas regulares, en el horizonte cruzan frecuentes conducciones hidráulicas elevadas que limitan el campo de visión; los caminos, también en resalte, son amplios y rectos, pero el principal cambio se debe al tapiz vegetal impuesto: largas filas de frutales en espaldera se entremezclan con una cubierta siempre verde de cereales de invierno y verano.

El único elemento atávico que lucha por sobrevivir es la laguna, con sus excepcionales inundaciones que invaden campos y caminos y devuelven al paisaje parte de su primitivo aspecto.

14 PONCE HERRERO, G., 1985, «Determinantes físicos y humanos del regadío en el Corredor de Almansa», en III Coloquio de Geografía Agraria, Jarandilla de la Vera, Universidad de Extremadura, 13 fols. meca., en prensa 